\title{
Potential molecular targets for inhibiting bone invasion by oral squamous cell carcinoma: a review of mechanisms
}

Jingjing Quan ${ }^{1}$, Newell W. Johnson ${ }^{2}$, Guangbiao Zhou ${ }^{3}$, Peter G. Parsons ${ }^{4}$, Glen M. Boyle ${ }^{4}$ and Jin $\mathrm{Gao}^{1,5^{*}}$

${ }^{1}$ School of Dentistry; Medical Science, Griffith University, QLD 4215, Australia

${ }^{2}$ Griffith Health Institute, Griffith University, QLD 4215, Australia

${ }^{3}$ Chinese Academy of Science, Beijing, the People's Republic of China

${ }^{4}$ Queensland Institute of Medical Research, Herston, Brisbane, QLD, Australia

${ }^{5}$ School of Medicine \& Dentistry, James Cook University, QLD 4870, Australia

* Corresponding to Jin Gao, School of Medicine \& Dentistry, James Cook University, QLD 4870, Australia. E-mail: jin.gao@jcu.edu.au. 


\begin{abstract}
Bone invasion is a common characteristic of oral squamous cell carcinoma (OSCC), with adverse affects on patient functionality and survival. Recent studies suggest that it is osteoclasts, rather than malignant keratinocytes themselves, which play the major role in facilitating the entry of the tumour into bone, and its progression within bone. Osteoclasts respond to a variety of local signaling pathways, initiated by products of the malignant epithelial cells themselves. In the present review, we firstly introduce the clinical patterns of bone invasion, and then summarize these signaling pathways and their diverse roles in sequential phases of bone invasion. We also review current researches regarding the incidence and mechanisms of distant metastases to bone, and explain briefly the concept of epithelial-mesenchymal transition (EMT), which may generate cancer stem cells (CSCs) and initiate the bone invasion. Finally, we discuss more briefly approaches to the diagnosis and management of OSCC patients with bone invasion. With all these studies and some recent discoveries in our own laboratory, an enhanced understanding of bone invasion will be achieved, which should indicate potential molecular targets for future biotherapies.
\end{abstract}

Keywords: Oral squamous cell carcinoma - Bone invasion · Molecular mechanisms $\cdot$ Signaling pathways $\cdot$ Biotherapy 


\section{Introduction}

Globally, "oral cancer" is the eighth most common cause of cancer-related death: more than $90 \%$ of oral malignancies are squamous cell carcinomas (OSCC) [1-3]. Lesions occurring in the retromolar trigone, gingiva, hard palate, buccal mucosa extending to sulci, or tongue extending to floor of mouth may involve bone of the maxilla and/or the mandible. The prevalence of mandibular bone involvement by OSCC is reported to range from 12 to $56 \%$ of cases [4-6]. Such patients commonly have severe dysfunction of speech, mastication and/or swallowing. Treatment and rehabilitation of cases involving bone is particularly challenging. Unfortunately, the cellular and molecular mechanisms of bone invasion by OSCC, and thus ways to prevent this, remain largely unknown. Understanding these mechanisms is essential in minimising spread and in planning surgical ablation, especially for guiding preservation surgery of the maxilla or mandible.

Pandey et al found that mandibular invasion was more common with tumours centred within $1 \mathrm{~cm}$ of the bone surface [7]. Two patterns of invasion are recognized: an infiltrative and an erosive form. In the infiltrative pattern, malignant keratinocytes advance into cancellous spaces in small clusters or chords with little osteoclastic activity. This requires portals of entry through the cortex, such as fenestrations on a resorbed alveolar ridge, an incompletely healed extraction socket, or perhaps the periodontal ligament [8]. In the erosive pattern, the neoplasm advances on a broad front, with an intervening connective tissue layer and active osteoclasts separating tumour from bone (Fig. 1) [9]. Some researchers have found progression from the erosive to the infiltrative pattern, as the extent of bone involvement increases [10]. The formation of these two patterns is likely to be influenced by anatomic details of the area of exposed bone, in particular whether the advancing front of the neoplasm meets compact or cancellous bone, by the intrinsic properties of the malignant cells themselves, by the properties of tumour stroma and factors unknown [11]. The recent observation that, amongst 21 cases of gingival SCC, transforming growth factor- $\beta$ (TGF- $\beta$ ) type I receptor was strongly expressed by tumour cells in all 14 cases which showed the infiltrative pattern, but in only 4/7 cases of erosive pattern, suggests that locally active signalling pathways alter cell behaviour to promote the different patterns of bone invasion [12]. 
Despite improvements in the treatment of OSCC, high recurrence rates and shorter survival have been reported in patients with bony invasion. Shaw et al prospectively reviewed 100 consecutive mandibular resections and conducted a follow up study of 65 months [9]. They found that 62 mandibles were invaded by carcinoma and $21 \%$ of these patients had a recurrence within the study period. The 5-year disease-specific survival rate was $61 \%$ for patients with mandibular invasion, compared to $80 \%$ for those without. Recently, Ardalan and his colleagues published another retrospective review, with a larger sample of 498 patients, 102 of whom had histologically proven invasion of bone at initial surgery [13]. After adjusting for other factors in a multivariate analysis, medullar invasion was the only independent predictor of reduced survival. The authors of both these studies recommended a revision of the current TNM staging system for OSCC, to include a component of bone invasion. These two substantial studies indicate the importance of detecting bone involvement in the planning of treatment and, if possible, finding ways to prevent it.

\section{Molecular Mechanisms}

Although little is known as to whether OSCC cells have the ability to resorb bone themselves, it is clear that osteoclasts are much involved in this process [14-16]. Osteoclasts differentiate at the bone surface and dissolve mineral components by an extracellular mechanism involving secretion of acid $[17,18]$. Several signalling pathways initiated by products of the neoplastic keratinocytes themselves are reported to affect osteoclast function, the latter including proteases, cytokines, and growth factors. Bone invasion is a highly coordinated process, spatially and temporally regulated and can be described as having three phases: initial, resorption and final phases. Various molecules orchestrate these phases and appear to play distinct roles in each phase. In the initial phase, while osteoclasts have not yet been recruited, proteases help to degrade the extracellular matrix (ECM) of surrounding soft tissues and facilitate the entry of malignant keratinocytes into the soft tissues or marrow spaces within the bone. The main phase of bone invasion is then the resorption phase, when osteoclasts take the main role to resorb the calcified components of bone. At this stage, cytokines generated from tumour cells directly or indirectly induce the formation of osteoclasts. Following osteoclast-mediated resoprtion, additional growth factors are liberated 
and these promote the growth of neoplastic cells themselves, thus driving a vicious cycle to accelerate the process of bone invasion.

\subsection{Proteases-Initial Phase}

Bone tissue consists of a number of distinct cell types and the bone matrix, which is largely mineralized. In the bone matrix, crystals of hydroxyapatite exist in association with both collagenous and noncollagenous proteins: the latter including osteocalcin, osteoprotein, osteonectin and calbindin [19, 20]. Osteocytes are incorporated within bone, together with numerous other cell types, such as osteoprogenitor cells, osteoblasts, osteoclasts, marrow fibroblasts, and undifferentiated cells, all of which participate in the process of continuous bone remodelling [19, 20]. Malignant keratinocytes produce a range of enzymes capable of destroying bone matrix directly, enhancing their migration into the adjacent soft tissue spaces [21]. Moreover, these proteolytic enzymes act on bone cells, especially osteoclast precursors, to promote their differentiation and maturation, thus causing further bone destruction. Two major groups of proteases play a part in bone invasion of OSCC: matrix metalloproteinases and cathepsins.

\subsubsection{Matrix Metalloproteinases}

Matrix metalloproteinases (MMPs) are a family composed of at lease 26 members. These are the main proteolytic enzymes responsible for digestion of fibrillar and non-fibrillar collagens, elastin, gelatine and proteoglycans [22]. Studies of the function of MMPs in vivo have also revealed that these proteases cleave and activate other extracellular protein substrates: indeed MMPs are involved in a variety of homeostatic functions including angiogenesis, wound healing and stimulation of immune responses [23].

Erdem et al showed that MMP-1 and MMP-9 were highly expressed in BHY cells, a cell line derived from a SCC of the lower alveolus which had deeply invaded into the mandible [24]. Using immunohistochemistry and flow cytometry, they also detected high levels of expression of extracellular matrix metalloproteinase inducer (EMMPRIN) in these cells. Another research group found that tumour tissues from 9 out of 24 cases of buccal SCC with mandibular invasion were stained strongly for active MMP-7, compared to 15 cases without invasion of the adjacent bone [25]. This is the first study demonstrating that MMP-7 is correlated with mandibular invasion, a significant observation which is consistent with the 
demonstration by others that secretion of MMP-7 by prostate and breast cancer cells is capable of cleaving the receptor activator of nuclear factor- $\kappa$ B ligand (RANKL) to an active soluble form, which then induces osteoclast formation and bone resorption [26, 27].

In our laboratory, we used an indirect cell co-culture model to investigate the cross-talk between osteoblasts and OSCC cells in vitro. We firstly collected conditioned medium (CM, without serum and cell debris) from either osteoblast (OB) or OSCC cells. Then OSCC cells were treated with $\mathrm{CM}$ of $\mathrm{OB}$ cells for $48 \mathrm{~h}$ and vice versa. We found that $\mathrm{CM}$ of $\mathrm{OB}$ could increase the expressions of MMP-2 in OSCC cells. For OB cells, when treated with CM of OSCC cells, MMP-9 expression was increased. We verified that these two molecules were indeed present in vivo, using immunohistochemistry on tissue sections of oral cancers invading bone: MMP-2 was weakly expressed while MMP-9 was strongly expressed within the cytoplasm of invading malignant keratinocytes (Fig. 2). This is consistent with other studies showing that MMP-2 and MMP-9, long known as key mediators of bone formation, and associated with invasion and metastasis of tumour cells [23], may also have important roles in the stimulation of bone invasion by OSCC.

\subsubsection{Cathepsins}

Cathepsins are members of the endosomal/lysosomal protease family, which are active at low $\mathrm{pH}$. They play an important role in bone degradation by osteoclasts. The cathepsin family has more than 21 members, divided into four subgroups: cysteine proteases, aspartic proteases, serine proteases and tripeptidyl proteases I [28]. Most, including cathepsins B and L, belong to the cysteine protease group; whereas cathepsins D and $\mathrm{E}$ are aspartic proteases.

Evidence for the role of cathepsins again comes from human studies, from animal experiments and from work with cell lines in vitro. Kawamata et al detected that BHY cells secreted a large amount of procathepsin L [29]. After injection into the masseter muscle of nude mice, BHY cells developed into highly differentiated squamous cell carcinomas which invaded the mandible, indicating that cathepsin L might help to degrade the bone matrix. This orthotopic animal model, in which tumour cells are injected adjacent to the mandible itself, has been used frequently in early studies of bone invasion [30]. However, based on our lab experience, injecting through the masseter muscle can cause discomfort and feeding 
difficulties for the animals, which may result in unexpected deaths in the middle of tumour development: This animal model needs to be improved. Another study showed that cathepsins B and D were strongly expressed in all 78 SCCs of tongue, gingiva or floor of mouth [31]. Using one way ANOVA, the labelling indices of both cathepsins had a significantly close correlation with degree of bone invasion. Further, in this case series, patients with high serum levels of cathepsins B and D had shorter survival times, suggesting these molecules may be of value as prognostic markers.

\subsection{Cytokines-Resorption Phase}

Osteoclasts are specific polykaryons, derived from monocyte/macrophage precursor cells [32]. It is known that two hematopoietic factors are necessary for osteoclastogenesis, receptor activator of nuclear factor- $\mathrm{B}$ ligand (RANKL) and polypeptide colony-stimulating factor-1 (CSF-1). In addition, other systemic hormones or cytokines regulate osteoclast function. In invasion of bone by OSCC, tumour-derived cytokines such as tumour necrosis factor$\alpha(\mathrm{TNF}-\alpha)$ can directly or indirectly induce the formation of osteoclasts, by stimulating RANKL or CSF-1 expression. Furthermore, interleukins (IL), a family of pleiotropic cytokines secreted by osteoblasts, osteoclasts, and stromal cells, have members which are important regulators of bone metabolism, especially IL-6 [19]. Another important molecule in bone homeostasis, parathyroid hormone related peptide (PTHrP), which functions to prevent apoptosis of osteoblasts and to recruit osteoclasts, has been shown to be up-regulated in clinical tissues of OSCC [33].

\subsubsection{TNF-related Proteins}

Recent studies have found that a family of TNF receptor (TNFR)/TNF-like proteins: osteoprotegerin (OPG), receptor activator of nuclear factor (NF)- $\kappa B$ (RANK), and RANKL, regulate osteoclast differentiation [34]. While RANKL is an inducer of bone resorption through its interaction with RANK, OPG is a soluble decoy receptor which acts as an inhibitor [35].

Ishikuro et al found that, of all 97 patients with gingival SCC, 45 cases were of the infiltrative type while the other 52 cases were of the erosive type [36]. In all cases, some fibrous 
connective tissues intervened between tumour and bone cells. However, there were more fibroblasts in the infiltrative type than the expansive type. To further explore the roles of fibrous stroma, immunohistochemistry was performed: this revealed that RANKL staining was mostly found in those fibroblasts in close apposition to osteoclasts. The authors also detected that BHY cells stimulated expressions of RANKL mRNA in mouse osteoblasts in cell co-culture experiments. Therefore, these results suggest that the neoplastic keratinocytes of gingival SCC may directly affect the fibrous stroma, which then plays promoting roles in osteoclastic bone resorption.

Tada et al showed that TNF $\alpha$ released from OSCC cells partially contributes to the generation of osteoclasts, and tumour-induced suppression of OPG may be critical [37]. When adding OPG into a co-culture between OSCC cells, mouse primary osteoblasts (POBs) and bone marrow cells (BMCs), osteoclast differentiation was significantly inhibited. This is consistent with the observation that OSCC cells did not enhance osteoclastogenesis in coculture between BMCs and POBs of OPG-deficient mice. These authors also examined the invaded mandibular lesions of 5 patients with OSCC, and found by immunohistochemsitry, a low expression of OPG in osteoblasts and other stromal cells, in comparison to normal bone from the same patients, which further confirmed their in vitro observations. This study is innovative in its research design, for it compared two types of established OSCC cell lines with bone invasive properties.

\subsubsection{Interleukins}

Osteoclasts and immune cells share many regulatory molecules, perhaps because many of the latter develop in the same microenvironment as osteoclasts: namely in bone marrow [38]. The finding that cultured human peripheral blood leukocytes can resorb bone is evidence of a relationship between immune response and bone metabolism [39]. The major mediator is now known to be interleukin-1 $\beta$ (IL-1 $\beta$ ) [40], but IL-6, IL-11 and IL-15 also stimulate bone resorption [41].

Okamoto et al found that BHY cells, which have a property of bone invasion, produced large amounts of IL-6, and CM from BHY cells markedly promoted pit formation by osteoclasts on mineralised substrates [42]. These authors also found that invasion of the mandible by BHY cells in nude mice was efficiently inhibited, when adding anti-IL-6 antibody to the cells 
before they were injected into the masseter muscle. IL-6 thus appears to be a strong mediator or enhancer of bone invasion by oral cancer.

Another study investigated 38 cases of SCC of the lower gingivae, which were classified by histopathology into invasive and non-invasive groups [43]. Immunohistochemistry showed that tumour cells were markedly more reactive for IL-6 and IL-11 in the group which invaded bone, whereas expression of IL-1 $\alpha$, IL-1 $\beta$ and IL-18 were not significantly different between the invasive and non-invasive groups. However, Van Cann et al found that expression of IL-6 and IL-11 were not significantly different between biopsy specimens of OSCC with or without medullar invasion [44] and suggested that immunohistochemical detection of these markers might not be an appropriate method to predict mandibular invasion.

\subsubsection{Parathyroid Hormone Related Peptide}

Parathyroid hormone related peptide (PTHrP), not parathyroid hormone (PTH) itself, was initially reported as a major factor related to malignancy-associated hypercalcaemia (MAH) [45]. PTHrP binds to its receptor, stimulates osteoclast activity and mediates bone destruction. It can also decrease expression of alkaline phosphatase (ALP) by osteoblasts, and their production of type I collagen, osteopontin, osteonectin, and osteocalcin [18, 19].

Deyama et al found that BHY cells naturally expressed high levels of PTHrP mRNA. Further, PTHrP mRNA could be detected from tumour tissues in 7 of 11 patients with carcinomas of the lower alveolus and gingiva, which showed an infiltrative pattern of bone involvement [46]. The same group also demonstrated in two further OSCC cell lines derived from cases with bone invasion, that PTHrP mRNA could be detected in abundance and could be significantly induced by epidermal growth factor (EGF), indicating that PTHrP may contribute to signalling downstream of EGFR [47].

Takayama et al showed that knock-down of PTHrP in OSCC cells caused dramatic reduction of osteoclast numbers in cell co-culture models [48]. Addition of TGF- $\beta$ induced expression of PTHrP, and generated epithelial-mesenchymal transition (EMT) of the oral cancer cell line, changes which might be expected to enhance bone invasion if these pathways were active in vivo. Consistent with this, they observed that tissue sections of carcinomas with mandibular 
invasion showed large numbers of osteoclasts, and strong expression of PTHrP in the tumour cells. E-cadherin staining of tumour cells was weaker at the bone resorption front than more centrally in the tumour mass, consistent with EMT-like changes. Taken together, these data suggest that PTHrP expression might have value as a predictor of bone involvement in OSCC.

\subsubsection{Chemokines}

Chemokines are small molecule cytokines, that exert their effect by binding to $G$ protein coupled 7-span trans-membrane receptors [49]. Some of these chemo-attractants are present in bone matrix and are thought to play a pivotal role in osteoclast activation. Furthermore, chemokines secreted by tumour cells themselves are also known to regulate recruitment and mobilization of osteoclasts [50].

Tang et al reported that the chemokine stromal cell-derived factor- $1 \alpha$ (SDF- $1 \alpha$ ), also named CXCL12, increased IL-6 expression in cultured OSCC cells, which further promoted osteoclast differentiation in co-culture models in vitro [51]. rhSDF-1 $\alpha$ increased the expression of its receptor CXCR4 in these OSCC cells, and CXCR4 inhibition abolished SDF-1 $\alpha$-induced IL-6 production. These authors further demonstrated that the pathways of

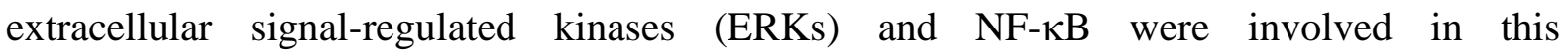
transcriptional regulation.

Pardrwrada et al found that both the chemokine ligand CXCL13 and its receptor CXCR5 were present in several OSCC cell lines, namely SCC1, SCC12 and SCC14a [52]. They demonstrated that recombinant human CXCL13 (rhCXCL13) could enhance the chemotaxis of peripheral blood monocytes in a dose-dependent manner, which would be expected to facilitate recruitment of osteoclasts. They injected OSCC cells onto the surface of calvaria in nude mice, where tumours developed in 4-5 weeks; histochemical staining then confirmed CXCL13 and CXCR5 expression, implying that CXCL13 may be considered as a prognostic marker for bone invasion in OSCC. This “calvaria-injection” animal model has the distinct advantage of causing animals limited stress as there is no interference with mastication, which is a risk when using oral or submasseteric sites.

\subsection{Growth Factors-Final Phase}


In addition to these cytokines, a variety of growth factors affect function of osteoblasts and osteoclasts during bone remodelling. Bone degradation in the progression of OSCC allows release of growth factors from reservoirs within mineralized matrix, such as epidermal growth factor (EGF), transforming growth factor (TGF), or connective tissue growth factor (CTGF), which may act as local regulators of tumour survival and bone resorption [53].

Huang et al found that the anti-EGF receptor (EGFR) antibody C225 could decrease migration abilities of SCC-1 cells [54]. Using a murine xenograft model, they detected that loco-regional invasion of SCC-1 cells into blood vessels, muscle and bone was efficiently inhibited in C225-treated mice. These data provide evidence that blockade of EGFR may suppress tumour-induced bony invasion as well as proliferation of the malignant keratinocytes themselves. Prime et al examined the malignant behaviour of several OSCC cell lines by transplanting them to the floor of the mouth in athymic mice [55]. They found that cell lines BICR31 and BICR56, which were resistant to TGF- $\beta 1$-induced growth inhibition, formed more primary tumours than those cells that were growth inhibited by TGF$\beta 1$. Furthermore, invasion of the mandible was commonly found: a high incidence of $30 \%$ and $44 \%$ respectively. These results suggest that OSCC cells unresponsive to TGF- $\beta 1$ behave more aggressively. Shimo et al investigated the role of CTGF in destruction of the mandible. Immunohistochemistry from 20 cases of mandibular SCC showed the presence of CTGF in osteoclasts and tumour cells [56]. In cultures of mouse bone marrow, rhCTGF stimulated the formation of tartrate resistant acid phosphatase (TRAP)-positive osteoclastlike cells. These results suggest that CTGF might be regarded as a diagnostic marker for the production of osteolytic lesions.

\section{EMT and Cancer Stem Cells}

We have attempted to summarise the processes discussed so far, and display the networks involved in direct invasion of bone by oral carcinomas, in Fig 3. In addition to these, studies

of the mechanisms by which distant bone metastases develop, which occur particularly with tumours of breast, prostate, thyroid, kidney and lung, encourage us to rethink the mechanisms of bone invasion. Following the initial stages of malignant transformation of keratinocytes, formation of a primary tumour, is associated with acquisition of a mesenchymal phenotype, a 
process now called EMT. Such cells are more active and migratoryleading to invasion into stroma, intravasation, dissemination and colonization of distant sites [57]. The hallmark of EMT is the disintegration of cell-cell junctions, particularly adherins junctions, and this dissociation is regulated by several transcription factors, in particular the zinc-finger proteins of Snail and Slug [58]. Accumulating evidence shows that a number of growth factors such as TGF- $\beta$ and EGF are potent effectors of EMT and are released into the microenvironment during the vicious cycle of formation of the neoplasm [59]. Moreover, EMT program has now been found to promote the self-renewal capability of carcinoma cells [60]. For example, TGF- $\beta$, which induces E-cadherin repressors; has been reported in the generation of cancer cells with higher stem cell properties that are capable of tumour initiation and regeneration [61].

EMT transformation is reported in the progression of bone invasion by OSCC. Maria et al showed that transfection of TGF- $\beta 1$ into a rat keratinocyte cell line caused changes in cell morphology from polygonal to spindle shaped in [62]. These spindle carcinoma cells formed more tumours with higher incidences of local bone resorption. A recent study reported that long term treatment of OSCC cells in vitro (6 days) with TGF- $\beta 1$ triggered EMT changes [63], which were associated with increased expressions of MMP-2 and MMP-9. However, a short period of treatment (3 days) induced only partial EMT, since the full morphological changes were not observed. But these changes could prolong the survival of mature osteoclasts and relate with bone invasion. Such findings generate a question of whether changes in the cellular morphology are needed for acquiring osteomimetic characteristics, since some of bone metastatic cancer cells are demonstrated to undertake phenotype changes and become fibroblast-like cells, with further expression of osteogenic molecules [64-66]. It is known that primary or metastatic cancers do not exist as isolated cells but, rather, they closely interact with a variety of stromal cell types [67, 68]. It is hard to speculate whether these tumour cells must have gone through phenotypic changes, since the EMT is transitory, in which there are technical difficulties to capture the whole process [60].

Cancer stem cells (CSCs), also known as tumour initiating cells, are a small subpopulation within a neoplasm: They exhibit a high capacity for promoting tumour growth, maintenance, metastatic progression, and are largely radioresistant and chemoresistant [69-71]. Malignant keratinocytes with EMT morphology and properties are typically found at the invasive front 
of primary tumours $[67,68]$, and as part of the invasion of bone by OSCC [48]. Could these be CSCs? Could growth factors, especially TGF- $\beta 1$, enrich the population of CSCs in OSCC with high invasive abilities? A potential model to examine these hypotheses may be the cell lines BICR31 and BICR56, which were resistant to TGF- $\beta 1$-induced growth inhibition, and formed more primary tumours with high properties of mandible invasion [55].

\section{Clinical Implications}

Oral squamous cell carcinomas which have invaded bone have a high recurrence rate, which dramatically impacts the patients' recovery and quality of life. Before starting treatment, a key point in diagnosis is to evaluate the presence and extent of tumour invasion into bone. At present, preoperative assessments usually consist of clinical examination, conventional radiography by orthopantomogram (OPG) and periapical radiographs, and if available, computerised tomography (CT), radionuclide bone scanning and magnetic resonance imaging (MRI) [72]. Other more sophisticated diagnostic tools such as multi-detector row CT (MDCT) or positron emission tomography/CT (PET/CT) have been shown to have a higher sensitivity in the assessment of bone invasion, but are not in routine use in most institutions $[73,74]$. An optimal combination of preoperative examination methods to predict bone invasion is necessary for the planning of definitive therapy for these patients [75].

The management of bone invasion in such patients remains controversial. Treatment choices include surgery, radiotherapy, chemotherapy and combinations thereof [76]. Most clinicians choose surgery as the primary therapy, with postoperative radiation or chemoradiation depending on the tumour extent and stage. When the maxilla or mandible is involved, marginal or segmental resection is needed and the primary aim of resection is to obtain clear surgical margins [77]. However, these resections may cause decreased function and cosmetic deformity. Therefore to maintain quality postoperative function, restoration of bone continuity is required, together with soft-tissue flaps to reconstruct the cosmetic defect. Postsurgical combined radiotherapy and chemotherapy are also helpful and are reported to increase the overall survival rate [78]. For example, Ly et al showed that similar outcomes would be achieved, between patients with bone or cartilage invasion treated with primary chemoradiotherapy (CRT) or resection followed by CRT [79]. However, the protocols of these postoperative therapies vary in different clinical centres and can only be applied in a 
subpopulation of OSCC patients. These supplemental therapies are also associated with a substantial increase in adverse effects, including severe mucositis or osteoradionecrosis, which would severely affect patients’ recovery and function [80

Recent studies of traditional Chinese herb medicine have attracted attention globally, as the increasing evidence shows bio-effects on a variety of diseases including the promising outcomes for the treatment of various cancers. Gambogenic acid (Fig. 4A) and 6-Oangeloylplenolin (Fig. 4B) are as such examples of the compounds. Gambogenic acid belongs to the diterpene series and is extracted from dry resin of Garcinia hanburyi [81, 82], while 6O-angeloylplenolin is a Compositae plant, a sesquiterpene lactone, isolated from Centipeda minima [83, 84]. The former shows its anti-cancer effects via inducing apoptosis [85], regulating the Bax and Bcl-2 family and enhancing the activity of caspase-3 in human melanoma cells. It also induced G1 phase cell cycle arrest and apoptosis through inactive Akt and mitochondrial oxidative stress in cells of nasopharyngeal carcinoma [86]. The latter demonstrates the bio-effect of anti-cancer on inhibiting the proliferation of cancer cells in human colorectum, liver, stomach, lung, and skin cancers [87], and on inducing cell apoptosis through a mitochondrial/caspase and NF- $\mathrm{BB}$ pathway in human HL-60 leukemia and myeloma [88, 89].

It would be very interesting to develop a new generation of bio-therapeutic agents from ancient Chinese herbs as anti-cancer drugs. At this time it is unclear if the compounds have anti-cancer bio-effects on inhibiting the initiation of cancer stem cells and bone invasion or metastasis, and what mechanisms if any are involved in these processes. Clearly, a great deal of work is to be done including mechanism of action studies and assessment of the clinical biosafety issues. However, these studies may open a bright future for cancer cure.

\section{Conclusions}

With the breakthrough in the biological target therapies, the treatment options for patients have been greatly expanded [90-92]. Some of the mediators discussed above have already been used as targets, such as the human monoclonal antibody targeting RANKL, Denosumab, which has been globally used and achieved outstanding effects in the phase 3 clinical trials of patients with prostate cancer [93]. RANKL inhibition by using recombinant OPG was also 
examined in patients with breast cancer or multiple myeloma with osteoclastic bone lesions [94]. Shin et al found that treatment with OPG decreased bone invasion of human OSCC B88 cells, while being injected into the masseter region of nude mice [95]. These examples have reminded researchers of the area of bone invasion. Efficient markers to quickly predict the presence of bone invasion, and effective targets to successfully treat the patients are needed for oral oncologists. As for the bone invasion, whilst the pathways are complex and interactive, molecular markers such as those described above would play a role in detecting the presence and extent of bone involvement. Furthermore, blockade of a variety of pathways including the initiation of cancer stem cells and EMT described in this review may open possibilities for future biotherapies with improved clinical outcomes.

\section{Authors delare to have no conflict of interest.}

Acknowledgement:we thank Professors Glenn Francis and Jane Dahlstrom for supplying tissue sections from oral cancer patients with bone invasion. This study was supported by funds from China Scholarship Council, Griffith University International Postgraduate Research Scholarship and Australian Dental Research Foundation.

\section{References}

1. Warnakulasuriya, S. (2009). Global epidemiology of oral and oropharyngeal cancer. Oral Oncol, 45(4-5), 309-316.

2. Johnson, NW., Jayasekara, P., \& Amarasinghe, AAHK. (2011). Squamous cell carcinoma and precursor lesions of the oral cavity: Epidemiology and aetiology. Periodontology 2000, 57(1), 19-37.

3. Johnson, NW., Warnakulasuriya, S., Gupta, PC., Dimba, E., Chindia, M., Otoh, EC., et al. (2011). Global Inequalities in Incidence \& Outcomes for Oral Cancer: Causes \& Solutions. Adv Dent Res, 23(2), 237-246. 
4. Chen, YL., Kuo, SW., Fang, KH., \& Hao, SP. (2011). Prognostic impact of marginal mandibulectomy in the presence of superficial bone invasion and the nononcologic outcome. Head Neck, 33(5), 708-713.

5. Lubek, J., El-Hakim, M., Salama, AR., Liu, X., \& Ord, RA. (2011). Gingival carcinoma: retrospective analysis of 72 patients and indications for elective neck dissection. Br J Oral Maxillofac Surg, 49(3), 182-185.

6. Hoffmannová, J., Foltán, R., Vlk, M., Sipos, M., Horká, E., Pavlíková, G., et al. (2010). Hemimandibulectomy and therapeutic neck dissection with radiotherapy in the treatment of oral squamous cell carcinoma involving mandible: a critical review of treatment protocol in the years 1994-2004. Int J Oral Maxillofac Surg, 39(6), 561-567.

7. Pandey, M., Rao, LP., Das, SR., Mathews, A., Chacko, EM., \& Naik, BR. (2007). Patterns of mandibular invasion in oral squamous cell carcinoma of the mandibular region. World J Surg Oncol, 30, 5-12.

8. Brown, JS., Lowe, D., Kalavrezos, N., D'Souza, J., Magennis, P., \& Woolgar, J. (2002). Patterns of invasion and routes of tumor entry into the mandible by oral squamous cell carcinoma. Head Neck, 24(4), 370-383.

9. Shaw, RJ., Brown, JS., Woolgar, JA., Lowe, D., Rogers, SN., \& Vaughan ED. (2004). The influence of the pattern of mandibular invasion on recurrence and survival in oral squamous cell carcinoma. Head Neck, 26(10), 861-869.

10. Brown, JS., \& Browne, RM. (1995). Factors influencing the patterns of invasion of the mandible by oral squamous cell carcinoma. Int J Oral Maxillofac Surg, 24(6), 417-426.

11. Ito, M., Izumi, N., Cheng, J., Sakai, H., Shingaki, S., Nakajima, T., et al. (2003). Jaw bone remodeling at the invasion front of gingival squamous cell carcinomas. J Oral Pathol Med, 32(1), 10-17.

12. Goda, T., Shimo, T., Yoshihama, Y., Hassan, NM., Ibaragi, S., Kurio, N., et al. (2010). Bone destruction by invading oral squamous carcinoma cells mediated by the transforming growth factor-beta signalling pathway. Anticancer Res, 30(7), 26152623.

13. Ebrahimi, A., Murali, R., Gao, K., Elliott, MS., \& Clark, JR. (2011). The prognostic and staging implications of bone invasion in oral squamous cell carcinoma. Cancer, 117(19), 4460-4467. 
14. Wysluch, A., Stricker, I., Hölzle, F., Wolff, KD., \& Maurer, P. (2010). Intraoperative evaluation of bony margins with frozen-section analysis and trephine drill extraction technique: A preliminary study. Head Neck, 32(11), 1473-1478.

15. Kayamori, K., Sakamoto, K., Nakashima, T., Takayanagi, H., Morita, K., Omura, K., et al. (2010). Roles of interleukin-6 and parathyroid hormone-related peptide in osteoclast formation associated with oral cancers: significance of interleukin-6 synthesized by stromal cells in response to cancer cells. Am J Pathol, 176(2), 968-980.

16. Martin, CK., Werbeck, JL., Thudi, NK., Lanigan, LG., Wolfe, TD., Toribio, RE., et al. (2010). Zoledronic acid reduces bone loss and tumor growth in an orthotopic xenograft model of osteolytic oral squamous cell carcinoma. Cancer Res, 70(21), 8607-8616.

17. Yavropoulou, MP., \& Yovos, JG. (2008). Osteoclastogenesis--current knowledge and future perspectives. J Musculoskelet Neuronal Interact, 8(3), 204-216.

18. Hadjidakis, DJ., \& Androulakis, II. (2006). Bone remodeling. Ann N Y Acad Sci, 1092, 385-396.

19. Raggatt, LJ., \& Partridge, NC. (2010). Cellular and molecular mechanisms of bone remodeling. J Biol Chem, 285(33), 25103-25108.

20. Georges, S., Ruiz, Velasco. C., Trichet, V., Fortun, Y., Heymann, D., \& Padrines, M. (2009). Proteases and bone remodelling. Cytokine Growth Factor Rev, 20(1), 29-41.

21. Woodward, JK., Holen, I., Coleman, RE., \& Buttle, DJ. (2007). The roles of proteolytic enzymes in the development of tumour-induced bone disease in breast and prostate cancer. Bone, 41(6), 912-927.

22. Krane, SM., \& Inada, M. (2008). Matrix metalloproteinases and bone. Bone, 43(1), 718.

23. Kessenbrock, K., Plaks, V., \& Werb, Z. (2010). Matrix metalloproteinases: regulators of the tumor microenvironment. Cell, 141(1), 52-67.

24. Erdem, NF., Carlson, ER., Gerard, DA., \& Ichiki, AT. (2007). Characterization of 3 oral squamous cell carcinoma cell lines with different invasion and/or metastatic potentials. J Oral Maxillofac Surg, 65(9), 1725-1733.

25. Chuang, HC., Su, CY., Huang, HY., Huang, CC., Chien, CY., Du, YY., et al. (2008). Active matrix metalloproteinase-7 is associated with invasion in buccal squamous cell carcinoma. Mod Pathol, 21(12), 1444-1450.

26. Thiolloy, S., Halpern, J., Holt, GE., Schwartz, HS., Mundy, GR., Matrisian, LM., et al. (2009). Osteoclast-derived matrix metalloproteinase-7, but not matrix 
metalloproteinase-9, contributes to tumor-induced osteolysis. Cancer Res, 69(16), 6747-6755.

27. Lynch, CC., Hikosaka, A., Acuff, HB., Martin, MD., Kawai, N., Singh, RK., et al. (2005). MMP-7 promotes prostate cancer-induced osteolysis via the solubilization of RANKL. Cancer Cell, 7(5), 485-496.

28. Goto, T., Yamaza, T., \& Tanaka T. (2003). Cathepsins in the osteoclast. J Electron Microsc (Tokyo), 52(6), 551-558.

29. Kawamata, H., Nakashiro, K., Uchida, D., Harada, K., Yoshida, H., \& Sato, M. (1997). Possible contribution of active MMP2 to lymph-node metastasis and secreted cathepsin L to bone invasion of newly established human oral-squamous-cancer cell lines. Int J Cancer, 70(1), 120-127.

30. Henson, B., Li, F., Coatney, DD., Carey, TE., Mitra, RS., Kirkwood, KL., et al. (2007). An orthotopic floor-of-mouth model for locoregional growth and spread of human squamous cell carcinoma. J Oral Pathol Med, 36(6), 363-370.

31. Kawasaki, G., Kato, Y., \& Mizuno, A. (2002). Cathepsin expression in oral squamous cell carcinoma: relationship with clinicopathologic factors. Oral Surg Oral Med Oral Pathol Oral Radiol Endod, 93(4), 446-454.

32. Boyle, WJ., Simonet, WS., \& Lacey, DL. (2003). Osteoclast differentiation and activation. Nature, 423(6937), 337-342.

33. Datta, NS., \& Abou-Samra, AB. (2009). PTH and PTHrP signaling in osteoblasts. Cell Signal, 21(8), 1245-1254.

34. Dougall, WC., \& Chaisson, M. (2006). The RANK/RANKL/OPG triad in cancerinduced bone diseases. Cancer Metastasis Rev, 25(4), 541-549.

35. Cochran, DL. (2008). Inflammation and bone loss in periodontal disease. J Periodontol, 79(8 Suppl), 1569-1576.

36. Ishikuro, M., Sakamoto, K., Kayamori, K., Akashi, T., Kanda, H., Izumo, T., et al. (2008). Significance of the fibrous stroma in bone invasion by human gingival squamous cell carcinomas. Bone, 43(3), 621-627.

37. Tada, T., Jimi, E., Okamoto, M., Ozeki, S., \& Okabe K. (2005). Oral squamous cell carcinoma cells induce osteoclast differentiation by suppression of osteoprotegerin expression in osteoblasts. Int J Cancer, 116(2), 253-262.

38. Nakashima, T., \& Takayanagi H. (2008). The dynamic interplay between osteoclasts and the immune system. Arch Biochem Biophys, 473(2), 166-171. 
39. Bar-Shavit, Z. (2007). The osteoclast: a multinucleated, hematopoietic-origin, boneresorbing osteoimmune cell. J Cell Biochem, 102(5), 1130-1139.

40. Dewhirst, FE., Stashenko, PP., Mole, JE., \& Tsurumachi, T. (1985). Purification and partial sequence of human osteoclast-activating factor: identity with interleukin 1 beta. J Immunol, 135(4), 2562-2568.

41. Walsh, MC., Kim, N., Kadono, Y., Rho, J., Lee, SY., Lorenzo, J, et al. (2006). Osteoimmunology: interplay between the immune system and bone metabolism. Annu Rev Immunol, 24, 33-63.

42. Okamoto, M., Hiura, K., Ohe, G., Ohba, Y., Terai, K., Oshikawa, T, et al. (2000). Mechanism for bone invasion of oral cancer cells mediated by interleukin-6 in vitro and in vivo. Cancer, 89(9), 1966-1975.

43. Shibahara, T., Nomura, T., Cui, NH., \& Noma, H. (2005). A study of osteoclastrelated cytokines in mandibular invasion by squamous cell carcinoma. Int J Oral Maxillofac Surg, 34(7), 789-793.

44. Van, Cann. EM., Slootweg, PJ., de, Wilde. PC., Otte-Höller, I., Koole, R., Stoelinga, PJ., et al. (2009). The prediction of mandibular invasion by squamous cell carcinomas with the expression of osteoclast-related cytokines in biopsy specimens. Int J Oral Maxillofac Surg, 38(3), 279-284.

45. Tsuchimochi, M., Kameta, A., Sue, M., \& Katagiri, M. (2005). Immunohistochemical localization of parathyroid hormone-related protein (PTHrP) and serum PTHrP in normocalcemic patients with oral squamous cell carcinoma. Odontology, 93(1), 61-71.

46. Deyama Y, Tei K, Yoshimura Y, Izumiyama Y, Takeyama S, Hatta M, et al. (2008). Oral squamous cell carcinomas stimulate osteoclast differentiation. Oncol Rep, 20(3), 663-668.

47. Yamada, T., Tsuda, M, Ohba, Y., Kawaguchi, H., Totsuka, Y., \& Shindoh, M. (2008). PTHrP promotes malignancy of human oral cancer cell downstream of the EGFR signaling. Biochem Biophys Res Commun, 368(3), 575-581.

48. Takayama, Y., Mori, T., Nomura, T., Shibahara, T., \& Sakamoto M. (2010). Parathyroid-related protein plays a critical role in bone invasion by oral squamous cell carcinoma. Int J Oncol, 36(6), 1387-1394.

49. Gronthos, S., \& Zannettino, AC. (2007). The role of the chemokine CXCL12 in osteoclastogenesis. Trends Endocrinol Metab, 18(3), 108-113. 
50. Bonfil, RD., Chinni, S., Fridman, R., Kim, HR., \& Cher, ML. (2007). Proteases, growth factors, chemokines, and the microenvironment in prostate cancer bone metastasis. Urol Oncol, 25(5), 407-411.

51. Tang, CH., Chuang, JY., Fong, YC., Maa, MC., Way, TD., \& Hung, CH. (2008). Bone-derived SDF-1 stimulates IL-6 release via CXCR4, ERK and NF-kappaB pathways and promotes osteoclastogenesis in human oral cancer cells. Carcinogenesis, 29(8), 1483-1492.

52. Pandruvada, SN., Yuvaraj, S., Liu, X., Sundaram, K., Shanmugarajan, S., Ries, WL., et al. (2010). Role of CXC chemokine ligand 13 in oral squamous cell carcinoma associated osteolysis in athymic mice. Int J Cancer, 126(10), 2319-2329.

53. Matsuo, K., \& Irie, N. (2008). Osteoclast-osteoblast communication. Arch Biochem Biophys, 473(2), 201-209.

54. Huang, SM., Li, J., \& Harari, PM. (2002). Molecular inhibition of angiogenesis and metastatic potential in human squamous cell carcinomas after epidermal growth factor receptor blockade. Mol Cancer Ther, 1(7), 507-514.

55. Prime, SS., Eveson, JW., Stone, AM., Huntley, SP., Davies, M., Paterson, IC., et al. (2004). Metastatic dissemination of human malignant oral keratinocyte cell lines following orthotopic transplantation reflects response to TGF-beta 1. J Pathol, 203(4), 927-932.

56. Shimo, T., Kubota, S., Goda, T., Yoshihama, Y., Kurio, N., Nishida, T., et al. (2008). Clinical significance and pathogenic function of connective tissue growth factor (CTGF/CCN2) in osteolytic mandibular squamous cell carcinoma. Anticancer Res, 28(4C), 2343-2348.

57. Van der Pluijm G. (2011). Epithelial plasticity, cancer stem cells and bone metastasis formation. Bone, 48(1), 37-43.

58. Polyak, K., \& Weinberg, RA. (2009). Transitions between epithelial and mesenchymal states: acquisition of malignant and stem cell traits. Nat Rev Cancer, 9(4), 265-273.

59. Sterling, JA., Edwards, JR., Martin, TJ., \& Mundy, GR. (2011). Advances in the biology of bone metastasis: how the skeleton affects tumor behavior. Bone, 48(1), 615.

60. Chaffer, CL., \& Weinberg, RA. (2011). A perspective on cancer cell metastasis. Science, 331(6024), 1559-1564. 
61. Mani, SA., Guo, W., Liao, MJ., Eaton, EN., Ayyanan, A., Zhou, AY., et al. (2008). The epithelial-mesenchymal transition generates cells with properties of stem cells. Cell, 133(4), 704-715.

62. Davies, M., Prime, SS., Stone, AM., Huntley, SP., Eveson, JW., \& Paterson, IC. (2000). Endogenous TGF-beta1 inhibits the growth and metastatic dissemination of rat oral carcinoma cell lines but enhances local bone resorption. J Oral Pathol Med, 29(5), 232-240.

63. Qiao, B., Johnson, NW., \& Gao, J. (2010). Epithelial-mesenchymal transition in oral squamous cell carcinoma triggered by transforming growth factor-beta1 is Snail family-dependent and correlates with matrix metalloproteinase-2 and -9 expressions. Int J Oncol, 37(3), 663-668.

64. Zhau, HE., Odero-Marah, V., Lue, HW., Nomura, T., Wang, R., Chu, G., et al. (2008). Epithelial to mesenchymal transition (EMT) in human prostate cancer: lessons learned from ARCaP model. Clin Exp Metastasis, 25(6), 601-610.

65. Odero-Marah, VA., Wang, R., Chu, G., Zayzafoon, M., Xu, J., Shi, C., et al. (2008). Receptor activator of NF-kappaB Ligand (RANKL) expression is associated with epithelial to mesenchymal transition in human prostate cancer cells. Cell Res, 18(8), 858-870.

66. He, H., Yang, X., Davidson, AJ., Wu, D., Marshall, FF., Chung, LW., et al. (2010). Progressive epithelial to mesenchymal transitions in ARCaP E prostate cancer cells during xenograft tumor formation and metastasis. Prostate, 70(5), 518-528.

67. Thompson, EW., \& Williams, ED. (2008). EMT and MET in carcinoma--clinical observations, regulatory pathways and new models. Clin Exp Metastasis, 25(6), 591592.

68. Onder, TT., Gupta, PB., Mani, SA., Yang, J., Lander, ES., \& Weinberg RA. (2008). Loss of E-cadherin promotes metastasis via multiple downstream transcriptional pathways. Cancer Res, 68(10), 3645-3654.

69. Lo, JF., Yu, CC., Chiou, SH., Huang, CY., Jan, CI., Lin, SC., et al. (2011). The epithelial-mesenchymal transition mediator S100A4 maintains cancer-initiating cells in head and neck cancers. Cancer Res, 71(5), 1912-1923.

70. Sethi, S., Macoska, J., Chen, W., \& Sarkar, FH. (2010). Molecular signature of epithelial-mesenchymal transition (EMT) in human prostate cancer bone metastasis. Am J Transl Res, 3(1), 90-99. 
71. Lo, WL., Yu, CC., Chiou, GY., Chen, YW., Huang, PI., Chien, CS., et al. (2011). MicroRNA-200c attenuates tumour growth and metastasis of presumptive head and neck squamous cell carcinoma stem cells. J Pathol, 223(4), 482-495.

72. Pentenero, M., Cistaro, A., Brusa, M., Ferraris, MM., Pezzuto, C., Carnino, R., et al. (2008). Accuracy of 18F-FDG-PET/CT for staging of oral squamous cell carcinoma. Head Neck, 30(11), 1488-1496.

73. Vidiri, A., Guerrisi, A., Pellini, R., Manciocco, V., Covello, R., Mattioni, O., et al. (2010). Multi-detector row computed tomography (MDCT) and magnetic resonance imaging (MRI) in the evaluation of the mandibular invasion by squamous cell carcinomas (SCC) of the oral cavity. Correlation with pathological data. J Exp Clin Cancer Res, 17, 29-73.

74. Abd, El-Hafez. YG., Chen, CC., Ng, SH., Lin, CY., Wang, HM., Chan, SC., et al. (2011). Comparison of PET/CT and MRI for the detection of bone marrow invasion in patients with squamous cell carcinoma of the oral cavity. Oral Oncol, 47(4), 288295.

75. Van, Cann. EM., Koole, R., Oyen, WJ., de, Rooy. JW., de, Wilde. PC., Slootweg, PJ., et al. (2008). Assessment of mandibular invasion of squamous cell carcinoma by various modes of imaging: constructing a diagnostic algorithm. Int J Oral Maxillofac Surg, 37(6), 535-541.

76. Ayad, T., Guertin, L., Soulières, D., Belair, M., Temam, S., \& Nguyen-Tân, PF. (2009). Controversies in the management of retromolar trigone carcinoma. Head Neck, 31(3), 398-405.

77. Guerra, MF., Campo, FJ., Gías, LN., \& Pérez, JS. (2003). Rim versus sagittal mandibulectomy for the treatment of squamous cell carcinoma: two types of mandibular preservation. Head Neck, 25(12), 982-989.

78. Scully, C., \& Bagan, J. (2009). Oral squamous cell carcinoma overview. Oral Oncol, 45(4-5), 301-308.

79. Do, L., Syed, N., Puthawala, A., Azawi, S., Williams, R., \& Vora, N. (2010). Prognostic significance of bone or cartilage invasion of locally advanced head and neck cancers. Am J Clin Oncol, 33(6), 591-594.

80. Hoffmannová, J., Foltán, R., Vlk, M., Sipos, M., Horká, E., Pavlíková, G., et al. (2010). Hemimandibulectomy and therapeutic neck dissection with radiotherapy in the treatment of oral squamous cell carcinoma involving mandible: a critical review of treatment protocol in the years 1994-2004. Int J Oral Maxillofac Surg, 39(6), 561-567. 
81. Zhao, L., Guo, QL., You, QD., Wu, ZQ., \& Gu, HY. (2004). Gambogic acid induces apoptosis and regulates expressions of $\mathrm{Bax}$ and $\mathrm{Bcl}-2$ protein in human gastric carcinoma MGC-803 cells. Biol Pharm Bull, 27(7), 998-1003.

82. Kasibhatla, S., Jessen, KA., Maliartchouk, S., Wang, JY., English, NM., Drewe, J., et al. (2005). A role for transferrin receptor in triggering apoptosis when targeted with gambogic acid. Proc Natl Acad Sci USA, 102(34), 12095-12100.

83. Oh, HM., Kwon, BM., Baek, NI., Kim, SH., Lee, JH., Eun, JS., et al. (2006). Inhibitory activity of 6-O-angeloylprenolin from Centipeda minima on farnesyl protein transferase. Arch Pharm Res, 29(1), 64-66.

84. Taylor, RS., \& Towers, GH. (1998). Antibacterial constituents of the Nepalese medicinal herb, Centipeda minima. Phytochemistry, 47(4), 631-634.

85. Xu, X., Liu, Y., Wang, L., He, J., Zhang, H., Chen, X., et al. (2009). Gambogic acid induces apoptosis by regulating the expression of Bax and Bcl-2 and enhancing caspase-3 activity in human malignant melanoma A375 cells. Int J Dermatol, 48(2), 186-192.

86. Yan, F., Wang, M., Chen, H., Su, J., Wang, X., Wang, F., et al. (2011). Gambogenic acid mediated apoptosis through the mitochondrial oxidative stress and inactivation of Akt signaling pathway in human nasopharyngeal carcinoma CNE-1 cells. Eur J Pharmacol, 652(1-3), 23-32.

87. Ding, LF., Liu, Y., Liang, HX., Liu, DP., Zhou, GB., \& Cheng, YX. (2009). Two new terpene glucosides and antitumour agents from Centipeda minima. J Asian Nat Prod Res, 11(8), 732-736.

88. Changlong, L., Hezhen, W., Yongping, H., Yanfang, Y., Yanwen, L., \& Jianwen, L. (2008). 6-O-Angeloylenolin induces apoptosis through a mitochondrial/caspase and NF-kappaB pathway in human leukemia HL60 cells. Biomedicine \& Pharmacotherapy, 62(6), 401-409.

89. Liu, Y., Chen, XQ., Liang, HX., Zhang, FX., Zhang, B., Jin, J., et al. (2011). Small compound 6-O-Angeloylplenolin induces mitotic arrest and exhibits therapeutic potentials in multiple myeloma. PLoS ONE, 6(7), e21930.

90. Ziober, BL., Mauk, MG., Falls, EM., Chen, Z., Ziober, AF., \& Bau, HH. (2008). Labon-a-chip for oral cancer screening and diagnosis. Head Neck, 30(1), 111-21.

91. Santini, D., Galluzzo, S., Zoccoli, A., Pantano, F., Fratto, ME., Vincenzi, B., et al. (2010). New molecular targets in bone metastases. Cancer Treat Rev, 36 Suppl 3, S6S10. 
92. Lee, RJ., Saylor, PJ., \& Smith, MR. (2011). Treatment and prevention of bone complications from prostate cancer. Bone, 48(1), 88-95.

93. Castellano, D., Sepulveda, JM., García-Escobar, I., Rodriguez-Antolín, A., Sundlöv, A., Cortes-Funes, H. (2011). The role of RANK-ligand inhibition in cancer: the story of denosumab. Oncologist, 16(2), 136-145.

94. Body, JJ., Greipp, P., Coleman, RE., Facon, T., Geurs, F., Fermand, JP., et al. (2003). A phase I study of AMGN-0007, a recombinant osteoprotegerin construct, in patients with multiple myeloma or breast carcinoma related bone metastases. Cancer, 97(3 Suppl), 887-892.

95. Shin, M., Matsuo, K., Tada, T., Fukushima, H., Furuta, H., Ozeki, S., et al. (2011). The inhibition of RANKL/RANK signaling by osteoprotegerin suppresses bone invasion by oral squamous cell carcinoma cells. Carcinogenesis, Sep 14. 
Legend:

Figure 1. Patterns of mandibular bone invasion. (A) The infiltrative pattern; (B) The erosive pattern. (Haematoxylin and eosin staining. Scale $=100 \mu \mathrm{m}$ )

Figure 2. Expression of MMP-2 and MMP-9 in immunohistochemical sections from OSCC with bone invasion (A) H\&E staining demonstrates an infiltrative pattern of bone invasion; (B) MMP-2 was weakly stained in the cytoplasm of invading malignant keratinocytes; (C) MMP-9 was strongly expressed.

Figure 3. Various molecules expressed from OSCC cells lead to the bone invasion through osteoclastogenesis. (A) In the initial phase, proteases help to degrade the ECM and facilitate OSCC cells entering into the bone tissue; (B) In the resorption phase, these cytokines generated from tumour cells directly or indirectly induce the formation of osteoclasts. (C) In the final phase, growth factors are liberated and promote the growth of OSCC cells, which drive the vicious cycle to accelerate the bone invasion process.

Figure 4. Structures of 6-O-Angeloylpenolin (A) and Gambogenic acid (B). 



Tumour cells Stromal cells Lymphocytes Osteoblasts Osteoclasts 


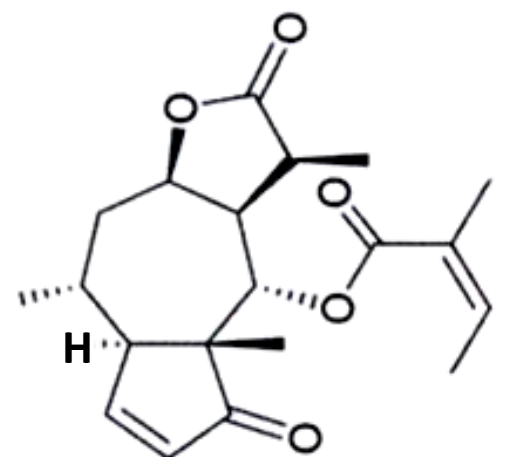

Structure of 6-O-angeloylp]

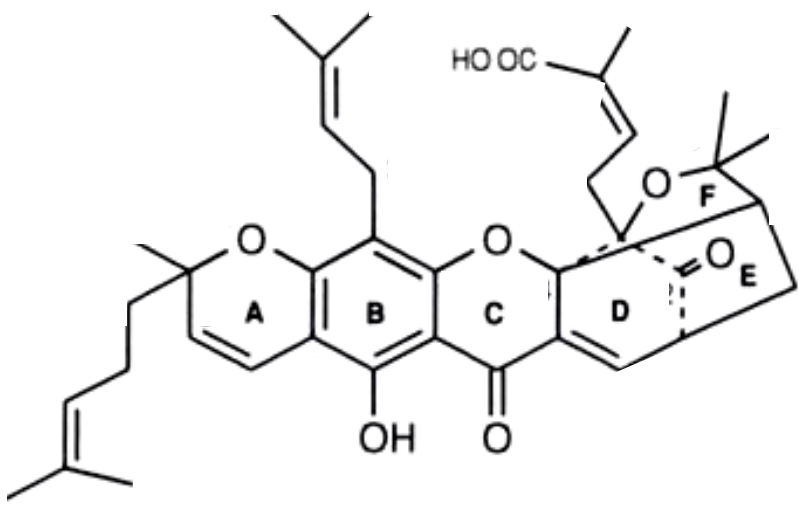

Structure of Gambogenic Acid 